\title{
Laboratory Investigation of Fatigue Characteristics of Asphalt Mixtures with Steel Slag Aggregates
}

\author{
Hassan Ziari, ${ }^{1}$ Shams Nowbakht, ${ }^{1}$ Sajad Rezaei, ${ }^{2}$ and Arash Mahboob ${ }^{2}$ \\ ${ }^{1}$ College of Civil Engineering, Iran University of Science \& Technology, Tehran 16846 13114, Iran \\ ${ }^{2}$ Department of Civil, Payame Noor University, P.O. Box 19395-3697, Tehran, Iran \\ Correspondence should be addressed to Arash Mahboob; arashmahboob@yahoo.com
}

Received 14 March 2015; Accepted 25 June 2015

Academic Editor: Robert Cerný

Copyright (c) 2015 Hassan Ziari et al. This is an open access article distributed under the Creative Commons Attribution License, which permits unrestricted use, distribution, and reproduction in any medium, provided the original work is properly cited.

\begin{abstract}
There are many steel-manufacturing factories in Iran. All of their byproducts, steel slag, are dumped randomly in open areas, causing many environmentally hazardous problems. This research is intended to study the effectiveness of using steel slag aggregate (SSA) in improving the engineering properties, especially fatigue life of Asphalt Concrete (AC) produced with steel slag. The research started by evaluating the physical properties of the steel slag aggregate. Then the 13 types of mixes which contain steel slag in portion of fine aggregates or in portion of coarse aggregates or in all portions of aggregates were tested. The effectiveness of the SSA was judged by the improvement in Marshall stability, indirect tensile strength, resilient modulus, and fatigue life of the AC samples. It was found that replacing the $50 \%$ of the limestone coarse or fine aggregate by SSA improved the mechanical properties of the AC mixes.
\end{abstract}

\section{Introduction}

Flexible pavements usually experience three major distresses including fatigue cracking, low temperature cracking, and rutting. Fatigue cracking is caused by repeated loading and it can result in significant reduction in the serviceability of flexible pavements. The fatigue performance of flexible pavement could be measured by cracking performance of asphalt mixtures in the laboratory [1].

Nowadays using waste materials in the asphalt paving industries is rapidly developing. The steel slag is a byproduct of steel manufacturing, which is obtained during the separation of molten steel from impurities in steel-making furnaces. One-ton stainless steel slag is obtained during production of 3 tons of stainless steel [2]. During production of steel, excess silicon and carbon are being removed from iron. In this process, furnace fills with iron or scrap metal, fluxing agent, lime stone, and coke as fuel. Carbon dioxide, which was removed from steel, combines with limestone, and forms steel slag [3].

Regarding the high frictional and abrasion resistance of steel slag, it has satisfactory performance in high traffic volume [4]. Asi et al. investigated skid resistances of asphalt concrete mixtures containing steel slag as an aggregate. In this study asphalt concrete containing 30\% steel slag had the best performance among other samples [5].

The steel slag has been utilized as coarse or fine aggregate in asphalt pavements and had a reliable response. One of the important considerations about steel slag is its expansion potential. Presence of free lime and magnesia in the steel slag makes it susceptible to wet condition and if it has been ignored, it may result in cracking [6]. For expansion problem the aggregate of asphalt mixture should be aged; for example, in washed coarse and fine steel slag aggregate the soft lime particles or lime-oxide agglomeration is less than $3 \%$ by mass of nonslag component [7].

$\mathrm{Wu}$ et al. investigated utilization of steel slag in stone mastic asphalt [8]. Asi et al. studied the effect of the steel slag aggregate on performance characteristics of hot mix asphalt. They conducted indirect tensile strength test, resilient modulus, rutting resistance, fatigue life, and creep modulus tests and also it was reported that mixtures containing up to $75 \%$ steel slag as a coarse aggregate had better mechanical properties than usual HMA [5]. 
TABLE 1: Engineering properties of aggregate sources.

\begin{tabular}{lccc}
\hline \multirow{2}{*}{ Test type } & \multicolumn{2}{c}{ Result } & Test method \\
& Limestone & Steel slag & \\
\hline $\begin{array}{l}\text { Bulk specific } \\
\text { gravity }\left(\mathrm{g} / \mathrm{cm}^{3}\right)\end{array}$ & 2.493 & 2.641 & ASTM C127 \\
$\begin{array}{l}\text { Absorption coarse } \\
\text { aggregate (\%) }\end{array}$ & 0.7 & 1.7 & ASTM C127 \\
$\begin{array}{l}\text { Absorption fine } \\
\text { aggregate (\%) }\end{array}$ & 1.6 & 2.4 & ASTM C128 \\
$\begin{array}{l}\text { Los Angeles } \\
\text { abrasion loss }(\%)\end{array}$ & 23.8 & 21.68 & AASHTO T96 \\
$\begin{array}{l}\text { Two fractured } \\
\text { faces (\%) }\end{array}$ & 94 & 96 & ASTM D5821 \\
\hline
\end{tabular}

TABLE 2: Gradations of designated aggregate.

\begin{tabular}{lc}
\hline Sieve size & Total cumulative passing \\
\hline $9.50 \mathrm{~mm}$ & $95 \%$ \\
$4.75 \mathrm{~mm}$ & $75 \%$ \\
$2 \mathrm{~mm}$ & $50 \%$ \\
$0.3 \mathrm{~mm}$ & $15 \%$ \\
$0.075 \mathrm{~mm}$ & $6 \%$ \\
\hline
\end{tabular}

TABLE 3: Asphalt binder properties.

\begin{tabular}{lcc}
\hline Property & Bitumen $60 / 70$ & Test method \\
\hline Specific gravity @25 $5^{\circ} \mathrm{C}\left(\mathrm{g} / \mathrm{cm}^{3}\right)$ & 1.03 & ASTM D-70 \\
Penetration @ $25^{\circ} \mathrm{C}(0.1 \mathrm{~mm})$ & 66 & ASTM D-5 \\
Softening point $\left({ }^{\circ} \mathrm{C}\right)$ & 53 & ASTM D-36 \\
Ductility @25 $5^{\circ} \mathrm{C}(\mathrm{cm})$ & 102 & ASTM D-113 \\
Flash point $\left({ }^{\circ} \mathrm{C}\right)$ & 305 & ASTM D-92 \\
Fire point $\left({ }^{\circ} \mathrm{C}\right)$ & 317 & ASTM D-70 \\
\hline
\end{tabular}

\section{Materials and Methods}

The aggregates selected in this study [9] were crushed limestone with a maximum nominal size of $9.5 \mathrm{~mm}$ from Tehran mine of cowboy horse. The steel slag used in this study is from Isfahan Steel Manufacturing Company. Their gradations and other properties are presented in Tables 1 and 2 .

The slag was sieved through $9.5 \mathrm{~mm}$ ( $3 / 8 \mathrm{in})$ sieve, to remove larger aggregates. For mitigation of expansion potential, the steel slag aggregates were washed. In this procedure hydration of free lime and magnesia was accelerated. One type of binder $(60 / 70 \mathrm{~mm} / 10$ grade $)$ chosen in this study is from Tehran Pasargadae Oil Company. Its properties are presented in Table 3.

2.1. Samples Preparation. Three different sets of mixtures, which consist of two different contents of steel slag aggregate, were prepared. In the first type $25 \%, 50 \%, 75 \%$, and $100 \%$ of the limestone coarse aggregate in the Asphalt Concretes (AC) were replaced by steel slag. In the second type $25 \%$, $50 \%, 75 \%$, and $100 \%$ of the limestone fine aggregates were replaced by steel slag and finally in the third type $25 \%, 50 \%$,
TABLE 4: Type of asphalt mixtures samples.

\begin{tabular}{lc}
\hline Mixture name & Type of steel slag aggregate combination \\
\hline Control & No steel slag aggregate \\
CSS-100 & $100 \%$ of coarse portion \\
CSS-75 & $75 \%$ of coarse portion \\
CSS-50 & $50 \%$ of coarse portion \\
CSS-25 & $25 \%$ of coarse portion \\
FSS-100 & $100 \%$ of fine portion \\
FSS-75 & $75 \%$ of fine portion \\
FSS-50 & $50 \%$ of fine portion \\
FSS-25 & $25 \%$ of fine portion \\
WSS-100 & $100 \%$ of whole aggregates \\
WSS-75 & $75 \%$ of whole aggregates \\
WSS-50 & $50 \%$ of whole aggregates \\
WSS-25 & $25 \%$ of whole aggregates \\
\hline
\end{tabular}

$75 \%$, and $100 \%$ of the whole aggregates were replaced by steel slag. Table 4 shows the specification of each mixture.

Optimum binder content was determined with Marshall method. Samples with 6 different (4-6) bitumen ratios were prepared at $0.5 \%$ increments. For each binder content three samples were prepared and 75 compaction blows for each side of sample were utilized.

Samples for Marshall test and sample for resilient modulus and indirect tensile strength test were compacted with Marshall hammer. For the beam fatigue samples, the mixture was first compacted using rolling wheel compacter and then specimens of size $63 \times 50 \times 380 \mathrm{~mm}$ were cut.

\subsection{Testing Programs}

2.2.1. Marshall Stability, Flow, and Marshall Quotient Test. Marshall test was performed on compacted specimens at various binder contents based on ASTM D 1559. Regarding bulk specific gravity, maximum stability, air voids in total mixture, and voids in aggregate filled with bitumen, the optimum binder content was selected [10].

2.2.2. Indirect Tensile Strength Test. The tensile property of asphalt concrete is evaluated through indirect tensile strength test [11]. Tensile strength of material shows maximum indirect tensile strength and strain in which material can endure before failing. In this test cylindrical specimen was loaded between two loading strips along the vertical diametrical plane which cause relatively uniform tensile stress along this plane. The tensile strength of specimen was determined by the following equation:

$$
\sigma=\frac{2 P}{\pi t d}
$$

where $\sigma$ is indirect tensile strength, $P$ is maximum load, $t$ is the thickness of specimen, and $d$ is the diameter of specimen.

2.2.3. Resilient Modulus. Resilient modulus (MR) is the most important parameter used in the mechanistic design of 


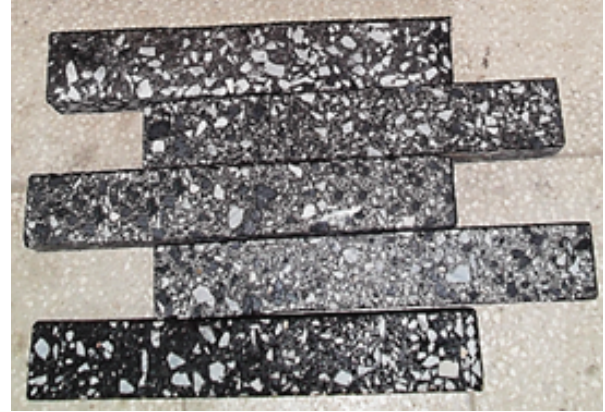

Figure 1: Some samples of beam fatigue.

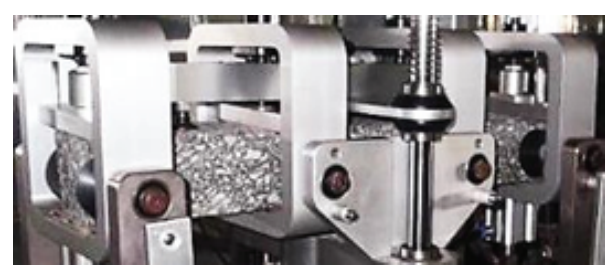

FIgURE 2: Sample under four-point beam fatigue test.

pavement structures. It is the measure of pavement response in terms of dynamic stresses and corresponding strains. Methods based on elastic theory require elastic properties of pavements as inputs.

The resilient modulus of bituminous mixtures, determined in accordance with ASTM D 4123 method, is the most popular form of stress-strain measurement used to evaluate the elastic properties of asphaltic mixtures at $25^{\circ} \mathrm{C}$ [12]. For each type of mixtures, three specimens were tested.

2.2.4. Four-Point Beam Fatigue Test. The beam fatigue test according to AASHTO T321-07 was utilized to evaluate fatigue life of asphalt mixtures. The test was performed under 600 strain levels at temperature of $25^{\circ} \mathrm{C}$. A repeated sinusoidal load was applied at frequency of $10 \mathrm{~Hz}$ without rest periods [13]. Three specimens were tested. Figures 1 and 2 show some specimens before and during the test, respectively.

\section{Results and Discussion}

3.1. Marshall Stability, Flow, and Marshall Quotient Test. Table 5 shows the result of Marshall test. The results are the mean value of three specimens. In general, steel slag increases Marshall stability and decreases flow. Effect of steel slag as a coarse aggregate replacement in improvement of Marshall stability is more significant than fine aggregate replacement.

WSS-100 has the highest Marshall stability among other mixtures. Because of steel slag aggregate structure, the use of steel slag generally enhances air void and this increment is more tangible in mixtures which have steel slag in their coarse portion.

3.2. Indirect Tensile Strength Test. The average values of indirect tensile strength tests for three specimens are shown

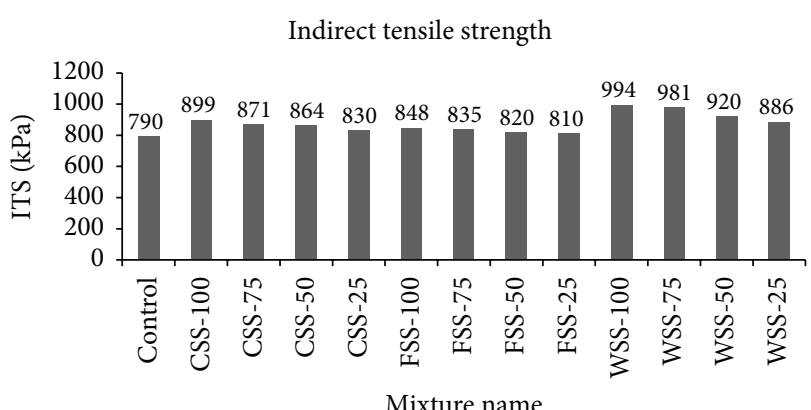

Figure 3: ITS test results of samples.

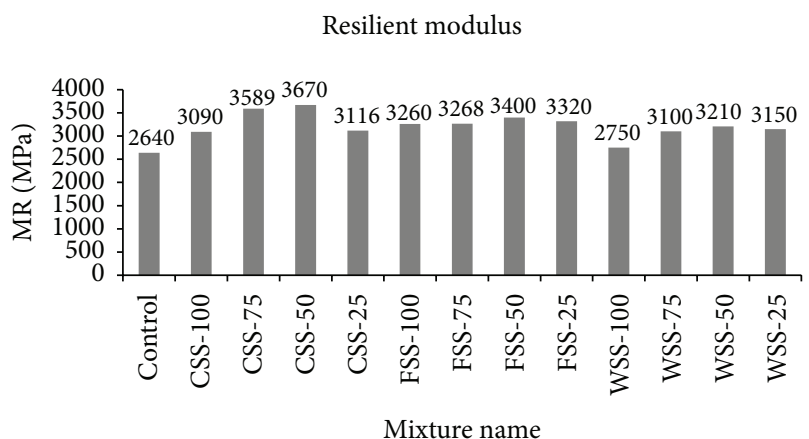

FIGURE 4: Resilient modulus of samples.

in Figure 3. It can be seen that all of the mixtures containing steel slag aggregate have high values of tensile strength. Mixtures containing steel slag in their coarse portions show the higher increase in the indirect tensile strength. This indicates that the structure of steel slag aggregate improves cohesion in asphalt mixtures. In coarse steel slag aggregates the effect of angularity is more significant than fine aggregates and this causes excessive increase in indirect tensile strength. WSS-100 has the most indirect tensile strength among other mixtures.

3.3. Resilient Modulus Test. Resilient modulus values for mixtures are presented in Figure 4. It indicates mixtures with steel slag aggregate have higher values of resilient modulus. Mixtures with $50 \%$ steel slag, as a virgin aggregate regardless of coarseness, fineness, or whole portion of aggregate, have better results in contrast to other mixtures. This can be attributed to higher binder content and stiffness of steel slag aggregates.

3.4. Fatigue Results. Figure 5 shows the results of 4-pointbeam fatigue test. The results are the average of three samples. In general steel slag increases the fatigue life of asphalt mixtures. This increment for mixture with steel slag aggregate in the coarse portion is about $15 \%$ but for mixtures with steel slag aggregate in their fine portion is about twice of control mixtures. An important consideration about utilization of steel slag is its expansion potential. Results indicate that mixtures with $100 \%$ steel slag aggregate have lower fatigue responses. In fatigue performance of steel slag asphalt mixtures, two 


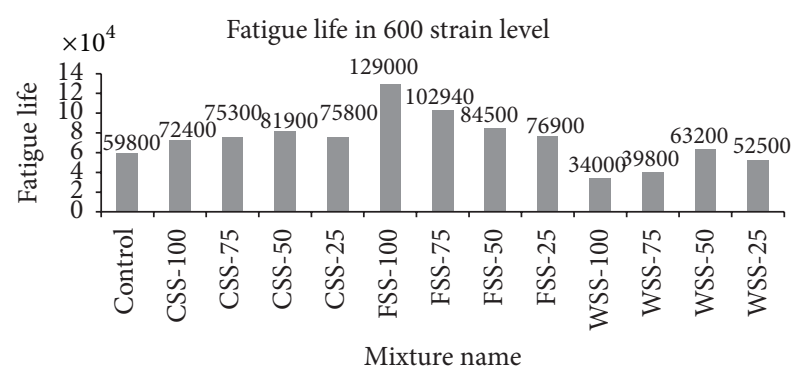

FIgURE 5: Fatigue life of samples in 600 strain levels.

TABLE 5: Marshall design results.

\begin{tabular}{lccccc}
\hline $\begin{array}{l}\text { Type of } \\
\text { mixture }\end{array}$ & $\begin{array}{c}\text { Optimum } \\
\text { binder } \\
\text { content }(\%)\end{array}$ & $\begin{array}{c}\text { Mix bulk } \\
\text { specific gravity } \\
\left(\mathrm{g} / \mathrm{cm}^{3}\right)\end{array}$ & $\begin{array}{c}\text { Air } \\
\text { void } \\
(\%)\end{array}$ & $\begin{array}{c}\text { Marshall } \\
\text { stability } \\
(\mathrm{kN})\end{array}$ & $\begin{array}{c}\text { Flow } \\
(\mathrm{mm})\end{array}$ \\
\hline Control & 5.2 & 2.41 & 4.49 & 8.9 & 3.21 \\
CSS-100 & 5.5 & 2.69 & 2.99 & 13.86 & 3.01 \\
CSS-75 & 5.1 & 2.61 & 3.31 & 13.2 & 3.11 \\
CSS-50 & 4.9 & 2.54 & 4.00 & 12.7 & 3.14 \\
CSS-25 & 5 & 2.50 & 4.14 & 12.1 & 3.4 \\
FSS-100 & 5.5 & 2.69 & 4.19 & 11.9 & 2.76 \\
FSS-75 & 5.4 & 2.99 & 4.02 & 11.6 & 2.97 \\
FSS-50 & 5.6 & 2.56 & 3.97 & 12.1 & 2.92 \\
FSS-25 & 5.2 & 2.49 & 3.82 & 11.3 & 2.74 \\
WSS-100 & 5.8 & 2.93 & 4.28 & 14.4 & 2.69 \\
WSS-75 & 5.8 & 2.89 & 3.97 & 13.6 & 2.87 \\
WSS-50 & 5.3 & 2.70 & 3.64 & 12.9 & 2.86 \\
WSS-25 & 5.3 & 2.60 & 3.49 & 11.15 & 3.03 \\
\hline
\end{tabular}

main characters of samples play a major role (first, air void and second, expansion potential). When steel slag aggregate replaces fine portion of limestone aggregate, the amount of increment in the air void is negligible; furthermore, washing of steel slag aggregate has more effect on decreasing the expansion potential of fine steel slag aggregate than coarse steel slag aggregate. According to these results, AC with 100\% steel slag aggregates (WSS-100) is not recommended.

\section{Conclusion}

According to the results obtained from Marshall and indirect tensile strength tests, mixtures with steel slag aggregate have better results in contrast to limestone asphalt mixtures and this can be due to the structure and angularity of steel slag aggregates. Fatigue tests results show that the use of steel slag aggregates in both fine and coarse portion of aggregate improves fatigue performance of asphalt mixtures, but 100\% steel slag asphalt mixtures have ineligible results in fatigue test. Replacement of steel slag aggregates as fine limestone aggregates has better results than coarse limestone aggregates. Better performance of fine steel slag aggregates is due to lower air void of these mixtures among other combinations of steel slag aggregate and limestone aggregates. Regarding performance of seven types of asphalt mixtures in all tests, mixtures with $50 \%$ steel slag aggregate in their fine, coarse, or whole aggregate have the best performance among other types of mixtures. In mixtures with 50\% steel slag aggregate, detrimental effect of excessive air void resulting from steel slag aggregate structures can be modified with excessive stiffness of these aggregates. According to the results of fatigue test, fine steel slag aggregate is a reliable alternative for limestone fine aggregates in places with high volume of traffic loading where fatigue cracking is much probable.

Suggestions for further studies in this field are as follows:

(i) laboratory evaluation of various bitumen in order to determine fatigue characteristics of asphalt mixtures with steel slag aggregates;

(ii) laboratory investigation of fatigue characteristics of asphalt mixtures with steel slag aggregate in the saturated condition;

(iii) laboratory evaluation of subzero temperatures on fatigue of asphalt mixtures with steel slag aggregate.

\section{Conflict of Interests}

The authors declare that there is no conflict of interests regarding the publication of this paper.

\section{Acknowledgments}

The authors would like to thank the officials and staffs of laboratories in Payame Noor University, Azad University of Germi, and Technical and Soil Mechanics Laboratory of Iran Ministry of Roads \& Urban Development.

\section{References}

[1] X. Shu, B. Huang, and D. Vukosavljevic, "Laboratory evaluation of fatigue characteristics of recycled asphalt mixture," Construction and Building Materials, vol. 22, no. 7, pp. 1323-1330, 2008.

[2] D. M. Proctor, K. A. Fehling, E. C. Shay et al., "Physical and chemical characteristics of blast furnace, basic oxygen furnace, and electric arc furnace steel industry slags," Environmental Science \& Technology, vol. 34, no. 8, pp. 1576-1582, 2000.

[3] P. S. Kandhal and G. L. Hoffman, "Evaluation of steel slag fine aggregate in hot-mix asphalt mixtures," Transportation Research Record, no. 1583, pp. 28-36, 1997.

[4] I. M. Asi, "Evaluating skid resistance of different asphalt concrete mixes," Building and Environment, vol. 42, no. 1, pp. 325-329, 2007.

[5] I. M. Asi, H. Y. Qasrawi, and F. I. Shalabi, "Use of steel slag aggregate in asphalt concrete mixes," Canadian Journal of Civil Engineering, vol. 34, no. 8, pp. 902-911, 2007.

[6] J. Norton, "Use of steel furnace slag in bituminous mixtures," Research Report 78 TB-23, Michigan Department of Transportation, Lansing, Mich, USA, 1979.

[7] B. Farrand and J. Emery, "Recent improvements in the quality of steel slag aggregate," Transportation Research Record, no. 1486, pp. 137-141, 1995.

[8] S. Wu, Y. Xue, Q. Ye, and Y. Chen, "Utilization of steel slag as aggregates for stone mastic asphalt (SMA) mixtures," Building and Environment, vol. 42, no. 7, pp. 2580-2585, 2007. 
[9] A. Mahboob, Providing a model of fatigue for steel slag aggregates in hot mix asphalt [M.S. thesis], Department of Civil Engineering, Payame Noor University (PNU), Tehran, Iran, 2014.

[10] ASTM, "Standard test method for resistance to plastic flow of bituminous mixtures using the Marshall apparatus," ASTM D 1559, American Society for Testing and Materials (ASTM), West Conshohocken, Pa, USA, 1989.

[11] ASTM, Standard Test Method for Indirect Tensile (IDT) Strength of Bituminous Mixtures (ASTM D6931), American Society for Testing and Materials (ASTM), West Conshohocken, Pa, USA, 2007.

[12] ASTM, Standard Test Method for Indirect Tension Test for Resilient Modulus of Bituminous Mixtures (ASTM D 4123), American Society for Testing and Materials (ASTM), West Conshohocken, Pa, USA, 1982.

[13] AASHTO, "Determining the fatigue life of compacted hot mix asphalt (HMA) subjected to repeated flexural bending," Test Procedure T321-07, American Association of State Highway and Transportation Officials (AASHTO), 2007. 

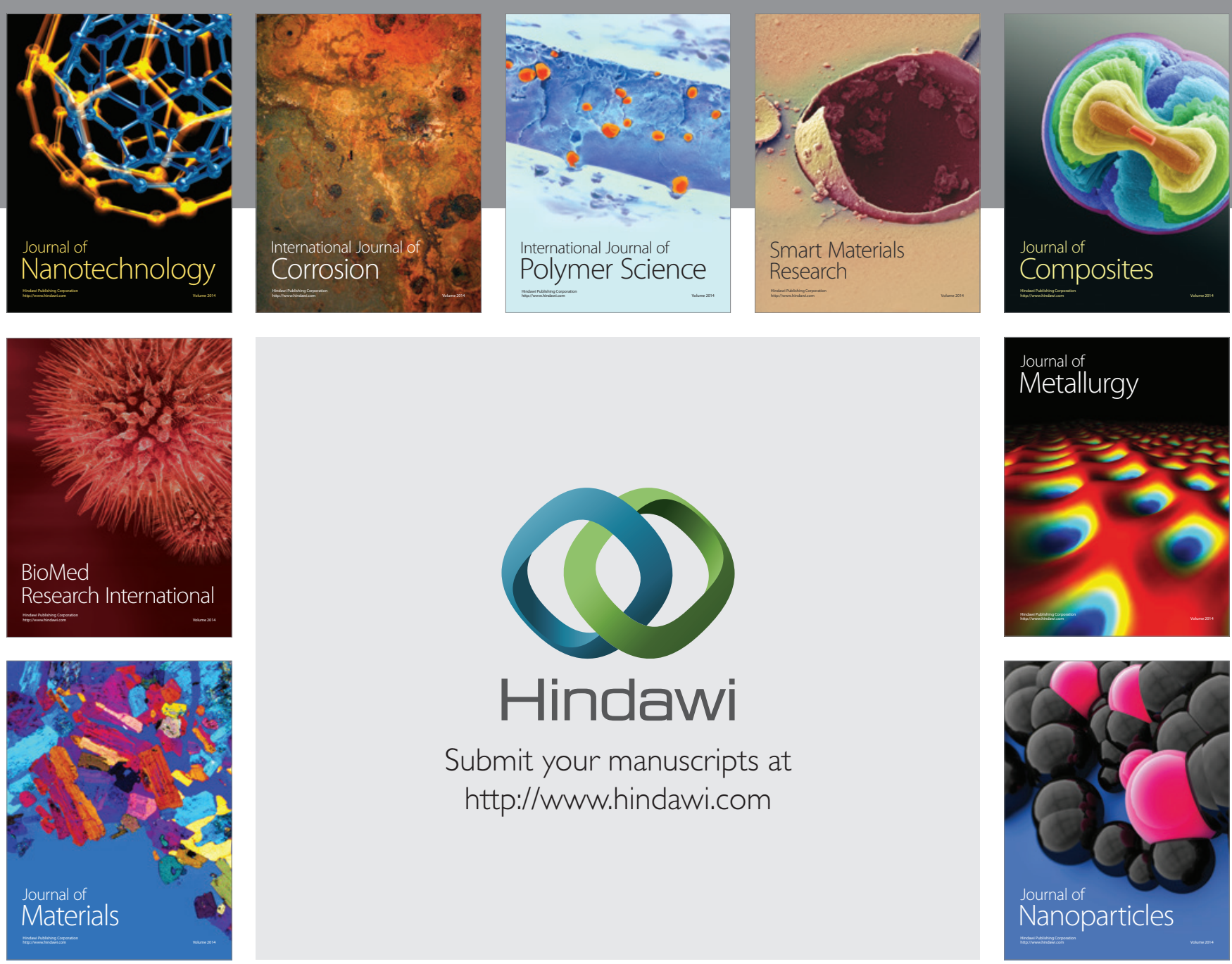

Submit your manuscripts at http://www.hindawi.com
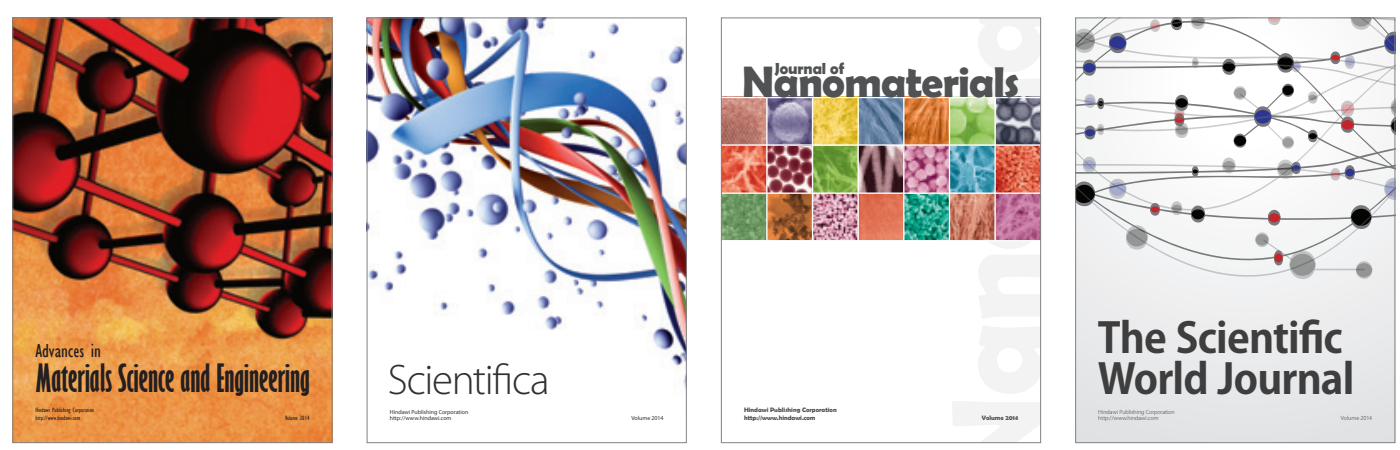

\section{The Scientific World Journal}
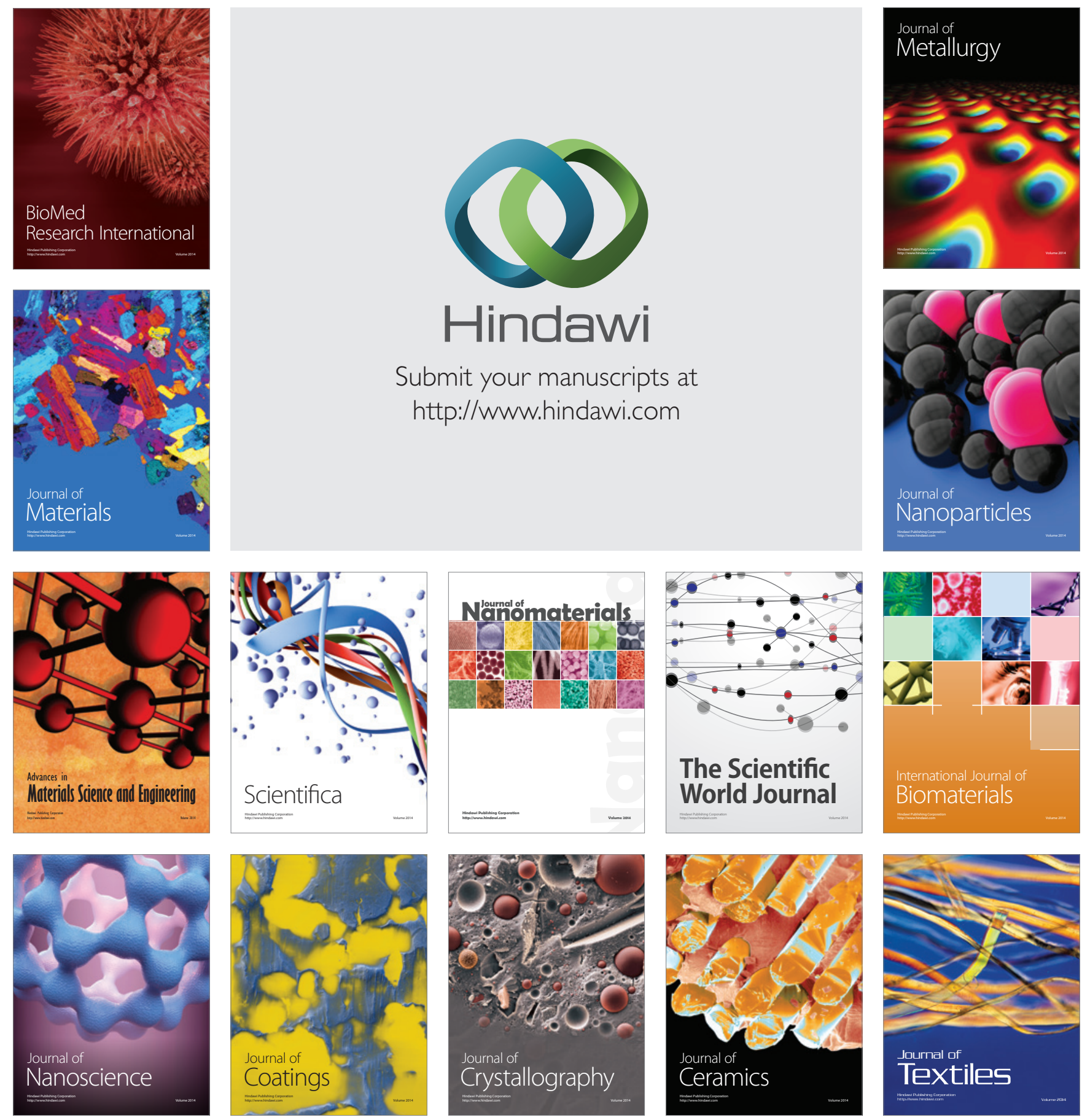